\title{
The payloads of planetary physics research onboard China's First Mars Mission (Tianwen-1)
}

\author{
WeiXing Wan ${ }^{1}$, Chi Wang' ${ }^{2}$, ChunLai Li ${ }^{3}$, Yong Wei', and JianJun Liü ${ }^{3 *}$ \\ ${ }^{1}$ Institute of Geology and Geophysics, Chinese Academy of Sciences, Beijing 100029, China; \\ ${ }^{2}$ National Space Science Center, Chinese Academy of Sciences, Beijing 100029, China; \\ ${ }^{3}$ National Astronomical Observatories, Chinese Academy of Sciences, Beijing 100012, China
}

Keywords: Mars; Tianwen-1; payload

Citation: Wan, W. X., Wang, C., Li, C. L., Wei, Y. and Liu, J. J. (2020). The payloads of planetary physics research onboard China's First Mars Mission (Tianwen-1). Earth Planet. Phys., 4(4), 331-332. http://doi.org/10.26464/epp2020052

\begin{abstract}
Mars is not only our nearby but also the most Earth-like planetary neighbor. Scientific exploration of Mars is thus of crucial value to our understanding of the solar system. The existence of abundant evidence for the former presence of water on Mars demands further exploration for signs of life on our sister planet, and investigations that could shed light on conditions favorable to the origin of life.
\end{abstract}

For nearly 60 years, humans have conducted orbitally-based remote sensing and in-situ surface exploration of Mars, leading to many significant scientific discoveries. But much remains to be done before we can be sure that we truly and fully understand Mars. Key research topics include the history of water on Mars and how that history relates to the planet's habitable environment past, present, and future; the distribution and evolution of waterbearing and evaporative salt minerals on the planet's surface; the history of volcanic activity on Mars; the Martian magnetic field and its effect on the escape of water and atmosphere from the planet; interactions between the solar wind and the Martian atmosphere and ionosphere; atmospheric characteristics and climate change on Mars; and so on (Li CL et al., 2018; Liu JJ et al., 2018). Based on the above scientific questions about life, climate, and geology on Mars, the international planetary science community has formulated ambitious Mars exploration programs.

In 2016, China announced extension of its planetary exploration program beyond the Earth-Moon system (Wei Y et al., 2018). Benefiting from the engineering heritage of China's lunar exploration program ( $\mathrm{Li} \mathrm{CL}$ et al., 2019), the Chinese national strategy set Mars as the next target for planetary exploration (Wan WX et al., 2020). China's first Mars mission, namely Tianwen-1, aims to complete orbiting, landing, and roving in one mission ( $\mathrm{Li} C L$ et al., 2018; Liu JJ et al., 2018). Orbiting exploration will establish an

Correspondence to: J. J. Liu, liujj@nao.cas.cn

Received 24 APR 2020; Accepted 15 JUN 2020.

Accepted article online 03 AUG 2020.

(C) 2020 by Earth and Planetary Physics. overall and integrated scientific picture of the planet through global, systematic remote sense observation. Landing patrol exploration, on the other hand, focuses on highly-accurate high-resolution exploration and in-situ analysis of key areas on the Martian surface.

To accomplish these objectives, the orbiter of China's first Mars exploration mission is equipped with seven payloads, including a Moderate Resolution Imaging Camera (MoRIC), a High Resolution Imaging Camera (HiRIC), a Mars Orbiter Scientific Investigation Radar (MOSIR), a Mars Mineralogical Spectrometer (MMS), a Mars Orbiter Magnetometer (MOMAG), a Mars Ion and Neutral Particle Analyzer (MINPA), and a Mars Energetic Particles Analyzer (MEPA). The mission's rover is equipped with six payloads, including a Mars surface Composition Detector (MarSCoDe), a Multispectral Camera (MSCam), a Navigation and Terrain Camera (NaTeCam), a Rover-mounted Subsurface Penetrating Radar (RoSPR), a Mars Rover Magnetometer (RoMAG), and a Mars Climate Station (MCS). Through independent explorations by the orbiter and the rover, as well as coordinated detections based on data simultaneously collected in orbit and on ground, scientific understanding of the Martian surface morphology, soil characteristics, material composition, water-ice, atmospheric ionosphere, and magnetic field can be realized. In terms of Mars space physics and exploration of the planet's space environment, data from the MINPA, MEPA, MO$M A G$, and even from the low-frequency radio receiver equipment carried by the orbiting spacecraft, can be combined with data from the RoMAG and MCS instruments on the rover to implement joint field and particle detections. In this way, we can systematically study the Martian atmosphere and ionosphere and their interactions with solar wind, and further reveal characteristics and evolution of the Martian space environment.

This EPP special issue systematically introduces the scientific goals, technical indicators, system design, calibration, and ground tests of six payloads, including the MINPA (Kong LG, 2020), MEPA (Tang SW, 2020), and MOMAG (Liu K, 2020) carried by the orbiter, and the MoRIC (Yu GB, 2020), RoSPR (Zhou B, 2020), and MCS 
(Peng YQ, 2020) mounted on the rover. We hope that publication of these technical papers describing details of China's first Mars exploration mission will facilitate production of "early, quick, and good scientific results".

Postscript: We are extremely sad that Prof. Weixing Wan, the Chief Scientist of Tianwen-1 and Editor-in-Chief of EPP, was unable to see this special issue through to completion, and to witness the launch of Tianwen-1. Regrettably, he passed away just several weeks before the launch date. (Chinese Geophysical Society, 2020; Wei Y, 2020). Prof. Wan was widely respected for his own scientific breakthroughs and for his leadership of an entire scientific community. The present and many future generations of the planetary community will long continue to benefit from his legacy. $\mathrm{He}$ will be greatly missed for his outstanding scientific achievements and his noble personality.

\section{References}

Chinese Geophysical Society. (2020). In memory of professor Weixing Wan. Earth Planet. Phys., 4(4), 329-330. https://doi.org/10.26464/epp2020051 Kong, L. G., Zhang, A. B., Tian. Z., Zheng, X. Z., Wang, W. J., Liu, B., Wurz, P., Piazza, D., Etter, A., Su, B., An, Y. Y., Ding, J. J., Li, W. Y., Liu, Y., Li, L., Li, Y. R., Tan, X. and Sun Y. Q. (2020). Mars lon and Neutral Particle Analyzer (MINPA) for Chinese Mars Exploration Mission (Tianwen-1): Design and ground calibration. Earth Planet. Phys., 4(4), 333-344. https://doi.org/10.26464/epp2020053

Li, C. L., Liu, J. J., Geng, Y., Cao, J. B., Zhang, T. L., Fang, G. Y., Yang, J. F., Shu, R., Zou, Y. L., ... Ouyang, Z. Y. (2018). Scientific objectives and payload configuration of China's first mars exploration mission. J. Deep Space Explor. (in Chinese), 5(5), 406-413. https://doi.org/10.15982/j.issn.20957777.2018 .05 .002

Li, C. L., Wang, C., Wei, Y., and Lin, Y. T. (2019). China's present and future lunar exploration program. Science, 365(6450), 238-239. https://doi.org/10.1126/science.aax9908

Liu, J. J., Su, Y., Zuo, W., Ren, X., Kong, D. Q., Wen, W. B., Zhang, H. B., and Li, C. L. (2018). Ground research and application system of China's first mars exploration mission. J. Deep Space Explor. (in Chinese), 5(5), 414-425. https://doi.org/10.15982/j.issn.2095-7777.2018.05.003

Liu, K., Zhang, T. L., Hao, X. J., Li, Y. R., Pan, Z. H., Chen, M. M., Hu, X. W., Shen, C. L. and Wang, Y. M. (2020). Mars orbiter magnetometer on Board Tianwen-1. Earth Planet. Phys., 4(4), 384-389. https://doi.org/10.26464/epp2020058

Peng, Y. Q., Zhang, L. B., Cai, Z. G., Wang, Z. G., Jiao, H. L., Wang, D. L., Yang, X. T., Wang, L. G., Tan, X., Wang, F., Fang, J., Sun, Z. L., Feng, H. L., Huang, X. R., Zhu, Y., Chen, M., Li, L. H., and Li, Y. H. (2020). Overview of the Mars climate station for Tianwen-1 mission. Earth Planet. Phys., 4(4), 371-383. https://doi.org/10.26464/epp2020057

Tang, S. W., Wang, Y., Zhao, H. Y., Fang, F., Qian, Y., Zhang, Y. J., Yang, H. B., Li, C. H., Fu, Q., Kong, J., Hu, X. Y., Su, H., Sun, Z. Y., Yu, Y. H., Zhang, B. M., Sun, Y., and Sun, Z. P. (2020). Calibration of Mars Energetic Particle Analyzer (MEPA). Earth Planet. Phys., 4(4), 355-363. https://doi.org/10.26464/epp2020055

Wan, W. X., Wang, C., Li, C. L., and Wei, Y. (2020). China's first mission to Mars. Nat. Astron., 4(7), 721. https://doi.org/10.1038/s41550-020-1148-6

Wei, Y. (2020). Weixing Wan. Nat. Astron., 4(7), 637-638. https://doi.org/10.1038/s41550-020-1140-1

Wei, Y., Yao, Z. H., and Wan, W. X. (2018). China's roadmap for planetary exploration. Nat. Astron., 2(5), 346-348. https://doi.org/10.1038/s41550-0180456-6

Yu, G. B., Liu, E. H., Liu, G. L., Zhou, L., Zeng, J. Z., Chen, Y. P., Zhou, X. D., Zhao, R. J., and Zhu, S. Y. (2020). Moderate Resolution Imaging Camera (MoRIC) of China's First Mars Mission Tianwen-1. Earth Planet. Phys., 4(4), 364-370. https://doi.org/10.26464/epp2020056

Zhou, B., Shen, S. X., Lu, W., Liu, Q., Tang, C. J., Li, S. D., and Fang, G. Y. (2020). The Mars rover subsurface penetrating radar onboard China's Mars 2020 mission. Earth Planet. Phys., 4(4), 345-354. https://doi.org/10.26464/epp2020054 